\title{
Class-specific rheumatoid factors, DR antigens, and amyloidosis in patients with rheumatoid arthritis
}

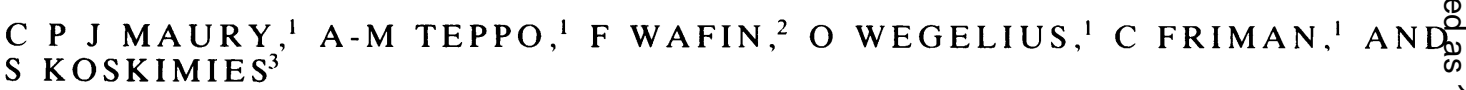

From the ${ }^{1}$ Fourth Department of Medicine, University of Helsinki; the ${ }^{2}$ Rheumatism Foundation Hospital $\stackrel{\circ}{\rightarrow}$ Heinola; and the ${ }^{3}$ Tissue Typing Laboratory, Finnish Red Cross Blood Transfusion Service, Helsinki, $\vec{\omega}$ Finland

SUMMARY Class-specific rheumatoid factors (RFs) were measured by enzyme immunoassay in. 59 patients with rheumatoid arthritis complicated by systemic amyloidosis $(\mathrm{RA}+\mathrm{A}), 47$ patients with rheumatoid arthritis without amyloid (RA), 106 patients with other rheumatic diseaseso (juvenile rheumatoid arthritis, systemic lupus erythematosus, Sjögren's syndrome), and 55 blood $^{J}$ donors. The patients with RA+A were characterised by a high prevalence of RF negativity; the $e_{\sqsubset}$ IgM RF concentration was raised in only 18 of the 59 patients $(31 \%, \mathrm{p}<0.001 v \mathrm{RA})$, the IgG RF< concentration in 20 of $59(34 \%, \mathrm{p}<0.001 v$ RA), and the IgA RF concentration in 24 of $59(41 \%, \overrightarrow{0}$ $\mathrm{p}<0.001 v \mathrm{RA})$. A higher prevalence of HLA-DR4 $(\mathrm{p}<0.001)$ and a lower prevalence of DR2.0 $(\mathrm{p}<0.05)$ were found among 48 tested patients with $\mathrm{RA}+\mathrm{A}$ when compared with a control panel consisting of 500 blood donors. No significant differences in the prevalence of DR1-DR7 or B27乡 antigens were observed, however, between patients with RA with or without amyloid.

Key words: IgM rheumatoid factor, IgG rheumatoid factor, IgA rheumatoid factor, HLA-B27 antigen.

The mechanism of amyloidogenesis in amyloidosis associated with rheumatic diseases is not known in detail. Persistently high concentrations of the circulating lipoprotein associated precursor protein serum amyloid $A$ and altered enzymatic degradation of the precursor and tissue amyloid A protein appear to be important factors. ${ }^{12}$ Only a small number of patients with these characteristics develop amyloid, however, suggesting the involvement of additional factors. Woo et al recently found that a DNA polymorphic site, $5^{\prime}$ to serum amyloid $\mathrm{P}$ component gene, is significantly associated with amyloidosis in patients with juvenile arthritis. ${ }^{3}$ The role of genetic factors in adult rheumatoid arthritis is, however, unclear. Studies on HLA antigens have had somewhat conflicting results. ${ }^{4-6}$ We have previously observed that in adult rheumatoid arthritis low values of circulating IgM, IgG, and IgA rheumatoid factors are associated with the occurrence of

Accepted for publication 30 December 1987.

Correspondence to $\mathrm{Dr} \mathrm{C}$ P J Maury, Fourth Department of Medicine, University of Helsinki, Unioninkatu 38, SF-00170 Helsinki, Finland. amyloidosis. ${ }^{7}$ This study examines more closely the rheumatoid factors, their isotypes and relation to inflammatory activity, and the prevalence of DRand B27 antigens in an extended patient populatione. with rheumatoid arthritis and associated amyloidosis?

\section{Subjects and methods}

RHEUMATOID FACTOR STUDY

We studied 212 patients with various rheumatic diseases as follows: The $\mathrm{RA}+\mathrm{A}$ patient groups consisted of 59 patients ( 40 women, 19 men; mearv age 54.4 years) with definite or classical rheumatoid arthritis ${ }^{8}$ complicated by secondary (reactive) amy loidosis proved by histological examination of renaf or rectal biopsy specimens, or both. The meare duration of the rheumatoid arthritis was $17 \cdot 3$ years Patients with ankylosing spondylitis, reactive arthri tis, and psoriatic arthritis as well as patients witlo juvenile onset rheumatoid arthritis were carefull excluded from the RA+A patient group. The $\mathrm{R}+\mathrm{D}^{\mathrm{T}}$ patient group consisted of 47 patients ( 33 women, 1 \& men; mean age 53.5 years) with definitive of classical rheumatoid arthritis ${ }^{8}$ with no clinical signe 
of amyloidosis. The mean duration of rheumatoid arthritis was 15.2 years. The JRA patient group consisted of 56 patients with juvenile rheumatoid arthritis (43 girls, 13 boys: mean age $10 \cdot 2$ years) without clinical signs of amyloidosis. The SS patient group consisted of 31 patients ( 26 women, five men: mean age 56 years) with primary ( 10 patients) or secondary (21 patients) Sjögren's syndrome. The SLE patient group consisted of 19 patients with systemic lupus erythematosus ( 18 women, one man; mean age 36.5 years). The healthy control subjects consisted of 55 blood donors (43 men, 12 women; mean age 37 years).

\section{HLA ANTIGEN STUDY}

The patient population consisted of a combination of a Heinola series and Helsinki series. The RA+A group comprised 48 patients with classical or definite rheumatoid arthritis ${ }^{8}$ ( 33 women, 15 men; mean age 50.8 years; mean duration of RA 18.4 years). The RA group consisted of 31 patients with classical or definite $\mathrm{RA}^{\mathrm{x}}$ (26 women, five men; mean age 52 years: mean duration of RA 20 years). Amyloidosis was excluded in these patients with RA by a negative staining for amyloid in rectal biopsy specimens. The control panel consisted of 500 Finnish voluntary blood donors who had been typed at the Finnish Red Cross, Helsinki.

\section{MEASUREMENT OF RF ISOTYPES}

Solid phase immunoassays were used to measure IgG, IgA, and IgM-type RFs. Polystyrene tubes were coated with swine IgG (Sigma Chemical Co, MO, USA) as follows: $1 \mathrm{ml}$ swine IgG (Sigma Chemical Co, MO, USA), $4 \mathrm{mg} / \mathrm{l}$ in $50 \mathrm{mM}$

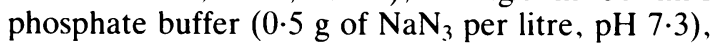
was incubated at $4^{\circ} \mathrm{C}$ overnight in polystyrene tubes. The tubes were then washed with distilled water, and $1 \mathrm{ml}$ of serum diluted 100 -fold with phosphate buffered saline containing $0.05 \%$ Tween 20 (PBSTween) was incubated in each tube at $4^{\circ} \mathrm{C}$ overnight to allow rheumatoid factors to bind to the surface adsorbed swine IgG. The alkaline phosphatase labelled, heavy chain specific swine antibodies to human IgG, IgA, or IgM (Orion Diagnostica, Espoo, Finland) (1 ml of 500 -fold diluted in PBSTween) were added and incubated at $37^{\circ} \mathrm{C}$ for one hour. The amount of alkaline phosphatase fixed to the tubes was determined in diethanolamine- $\mathrm{MgCl}_{2}$ buffer, $\mathrm{pH} 10$, at $37^{\circ} \mathrm{C}$ with $p$-nitrophenyl phosphate as substrate. The concentration of rheumatoid factors is expressed as a change in absorbance $(\triangle \mathrm{A})$ at $406 \mathrm{~nm}$ during 30 minutes. In each assay a positive (Waaler-Rose titre 1/1280; test dilutions of $1: 100$, $1: 200,1: 400$, and $1: 800)$ and a negative $(1: 100$ dilution) control serum were included. To eliminate the possible interference of the non-RF IgG in the IgG RF assay we determined the IgG-type RFs both before and after the removal of IgG by pepsin digestion. ${ }^{9}$ The removal of non-RF IgG did not increase the amount of IgG RF in any of the sera. Therefore in this study the values of IgG RFs obtained without pepsin treatment are reported. Addition of purified non-rheumatoid factor IgG, $\operatorname{IgA}$, and IgM to the RF positive and RF negative sera did not increase the concentration of respective RFs in any case by more than 5\% (Hannonen $\mathrm{P}$ et al, unpublished data), indicating thus minimal nonspecific binding of non-RF protein.

\section{HLA TYPING}

HLA typing was carried out with peripheral blood lymphocytes using the two stage microcytotoxicity assay described by Amos et al. ${ }^{\text {(1) }}$

\section{STA TIS TICS}

Statistical significances were assessed using the $\chi^{2}$ test and Wilcoxon's ranking test for unpaired data. In this study only previously described HLA antigen associations were tested for statistical difference; hence the $p$ values were not adjusted for the effect of multiple comparisons. ${ }^{11}$

\section{Results}

Figs 1-3 show the concentrations of class-specific RFs in the rheumatic patients. When compared with patients with RA without amyloid, the patients with $\mathrm{RA}+\mathrm{A}$ had significantly more often RF concentrations within the range of those of the normal subjects (IgM RF, $\mathrm{p}<0.001$; IgG RF, $\mathrm{p}<0.001$; IgA RF, $p<0 \cdot 001$ ). With respect to IgG RF, the patients with RA+A did not differ significantly from the patients with JRA. Serum samples of patients with SLE frequently contained both IgG RF (7/19 $(37 \%))$ and IgA RF (9/19 (47\%)).

There was no significant difference in $\mathrm{C}$ reactive protein (CRP) concentrations between the patients with RA+A and those with RA alone. When the patients with RA+A or RA were divided into two groups with differing inflammatory activity, as measured by CRP, no significant differences were found in the class-specific RF concentrations between patients with CRP concentrations $\geqslant 25 \mathrm{mg} / \mathrm{l}$ or $<25 \mathrm{mg} / \mathrm{l}$. (Table 1). Follow up of individual patients with RA+A showed some fluctuation in the RF concentrations. Fig. 4 illustrates the variations in class-specific RF concentrations in relation to the variation in Waaler-Rose titre and CRP concentration in a Waaler-Rose positive patient with $\mathrm{RA}+\mathrm{A}$, and Fig. 5 the variations observed in a Waaler-Rose negative (titre $<20$ ) patient with 
548 Maury, Teppo, Wafin, Wegelius, Friman, Koskimies

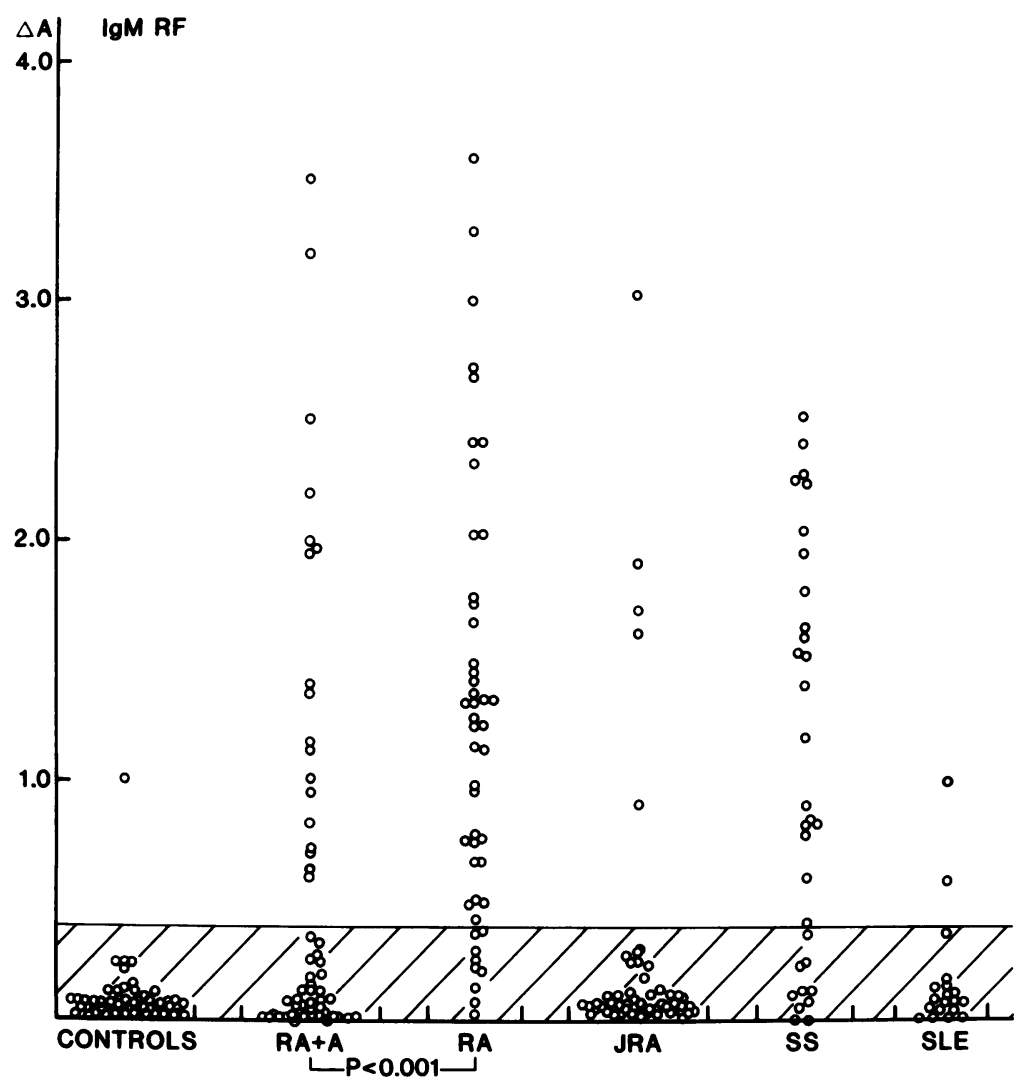

Fig. 1 IgM $R F$ values in rheumatic diseases. $\triangle A=$ change in absorbance at $406 \mathrm{~nm}$ during 30 minutes.

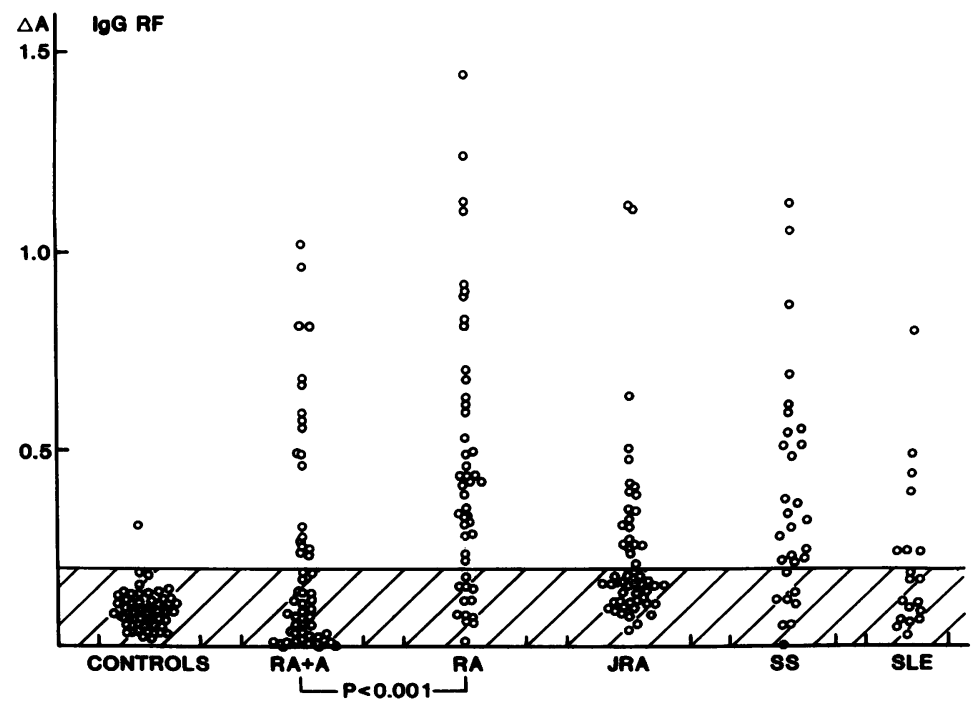

Fig. 2 IgG RF values in rheumatic diseases. $\triangle A=$ change in absorbance at $406 \mathrm{~nm}$ during 30 minutes. 


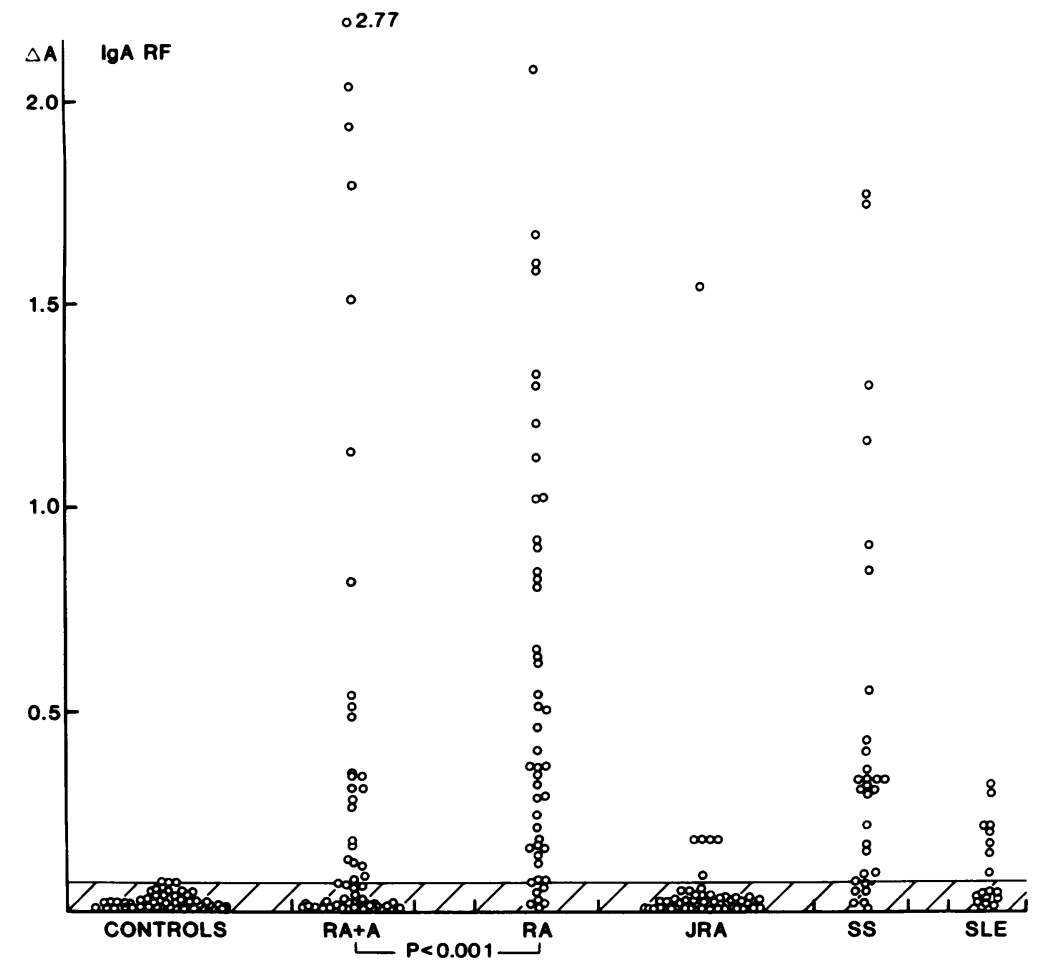

Fig. 3 IgA $R F$ values in rheumatic diseases. $\triangle A=$ change in absorbance at $406 \mathrm{~nm}$ during 30 minutes.

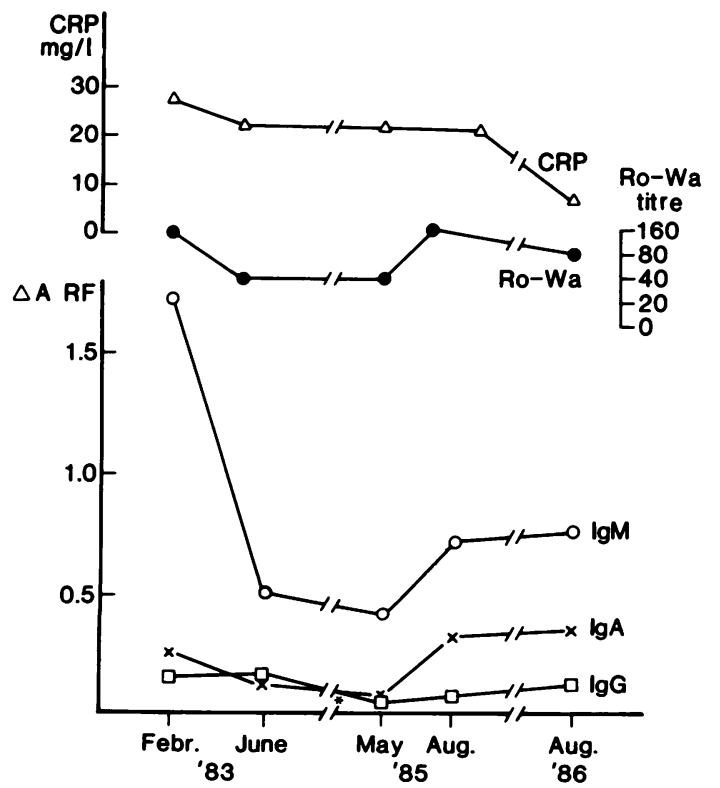

Fig. 4 Changes in the serum concentrations of CRP and $R F$ and in the Waaler-Rose titres during follow up of $a$ Waaler-Rose positive patient with rheumatoid arthritis and amyloidosis.
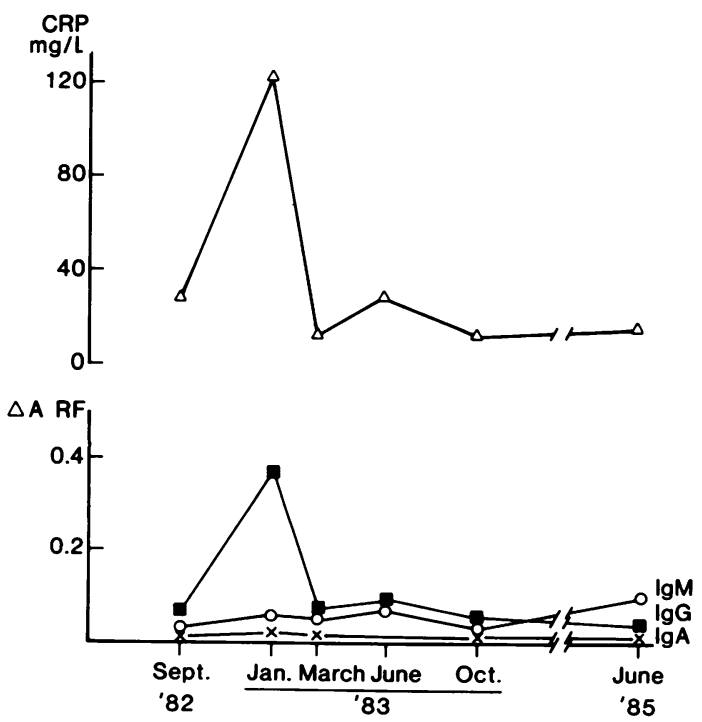

Fig. 5 Changes in the serum concentrations of $R F$ and $C R P$ during follow up of a Waaler-Rose negative patient with rheumatoid arthritis and amyloidosis. 
Table $1 \operatorname{Ig} M, \operatorname{Ig} G$, and $\operatorname{Ig} A R F$ values in patients with $R A$ and $R A+A$ with a serum $C$ reactive protein (CRP) concentration of either $\geqslant 25 \mathrm{mg} / \mathrm{l}$ or $<25 \mathrm{mg} / \mathrm{l}$

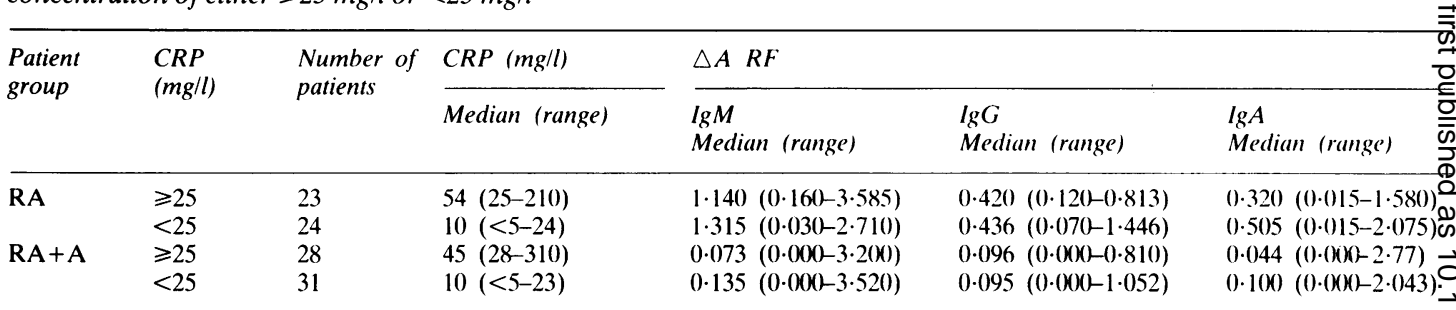

The differences in RF values between the subgroups with CRP $\geqslant 25 \mathrm{mg} / \mathrm{l}$ or $<25 \mathrm{mg} / \mathrm{l}$ are not significant.

$\mathrm{RA}+\mathrm{A}$. In the latter patient the changes in IgG RF and CRP concentrations paralleled each other.

At the time of sampling 35 of the 59 patients with $\mathrm{RA}+\mathrm{A}$ had a Waaler-Rose titre $<20(\mathrm{p}<0.001 v$ patients with RA). Retrospective review of previously measured Waaler-Rose titres showed that 26 of the 59 patients with RA+A had been WaalerRose negative during the whole disease period $(\mathrm{p}<0.05 v$ RA group $)$; in nine patients with RA +A a conversion of a Waaler-Rose positivity to negativity had occurred.

No significant differences were observed in the prevalence of the tested HLA antigens between patients with RA with or without amyloid (Table 2). A higher prevalence of DR4 $(p<0.001)$ and a lower prevalence of DR2 $(p<0.05)$ were found among the patients with RA+A as well as all patients with RA when compared with the normal population.

Table $2 H L A-D R$ and $B 27$ prevalence $(\%)$ in patients with $R A+A$, patients with $R A$ (combined Helsinki and Heinola series), all patients with $R A$, and in the Finnish voluntary blood donors

\begin{tabular}{lllll}
\hline Antigen & $\begin{array}{l}\text { Patients } \\
\text { with } R A+A \\
(n=48)\end{array}$ & $\begin{array}{l}\text { Patients } \\
\text { with } R A \\
(n=31)\end{array}$ & $\begin{array}{l}\text { All patients } \\
\text { with } R A \\
(n=79)\end{array}$ & $\begin{array}{l}\text { Finnish blood } \\
\text { donors } \\
(n=500)\end{array}$ \\
\hline B27 & $22 \cdot 9$ & $16 \cdot 1$ & $20 \cdot 2$ & $14 \cdot 0$ \\
DR1 & $45 \cdot 8$ & $32 \cdot 3$ & $40 \cdot 5$ & $38 \cdot 6$ \\
DR2 & $18 \cdot 8^{*}$ & $25 \cdot 8$ & $21 \cdot 5^{*}$ & $34 \cdot 0$ \\
DR3 & $20 \cdot 8$ & $25 \cdot 8$ & $22 \cdot 7$ & $24 \cdot 0$ \\
DR4 & $58 \cdot 3^{* *}$ & $48 \cdot 4$ & $54 \cdot 4^{* *}$ & $29 \cdot 5$ \\
DR5 & $14 \cdot 6$ & $6 \cdot 0$ & $11 \cdot 3$ & $10 \cdot 2$ \\
DR6 & $2 \cdot 1$ & $9 \cdot 7$ & $5 \cdot 1$ & $8 \cdot 3$ \\
DR7 & 16.6 & 16.1 & 16.4 & $12 \cdot 0$ \\
\hline
\end{tabular}

${ }^{*} \mathrm{p}<0.05 v$ control population; ${ }^{* *} \mathrm{p}<0 \cdot 001 v$ control population. The differences between the patients with RA+A and patients with RA are not significant.

\section{Discussion}

The present results show that the subset of patient with RA who have amyloidosis have lower conceno trations of circulating IgM, IgG, and IgA RFs than the patients with RA with no clinical signs of amyloid disease. The RA+A and RA patie groups were comparable with respect to age, sexট duration of RA, and inflammatory activity $\infty$ expressed by CRP concentrations, so these factors are not likely to have influenced the results. The patient groups were not directly matched for the use of drugs, but a review of the clinical records showe that the patients in both groups used, or had beef using, the same type of drugs, including steroids an gold salts. As uraemia may be immunosuppressive the question arises whether the high prevalence of RF negativity among the amyloid patients may hav resulted from the amyloid state itself. Many of the amyloid patients were, however, not uraemic, an ब्व retrospective review of previously measuref Waaler-Rose titres showed that in only nine case had a conversion from a seropositive to a seronegd tive state occurred. It is thus unlikely that the resulf can be explained on this basis only, though if appears possible that the amyloid state as well as differences in drug treatment ${ }^{13}{ }^{14}$ may have in fluenced the absolute concentrations of circulating RFs.

Previous studies have demonstrated positive associations of HLA-DR4, Dw4, and DRw5 and negative associations of DR2 and DR7 with RA ${ }^{15-19}$ Stronger associations were found in patierif subsets with seropositivity, severe erosions, and extra-articular disease. In accordance with thes studies we found a significantly higher prevalence of DR4 and a lower prevalence of DR2 in the patients with RA. The patients with RA+A, however, di not differ significantly from the patients with $R$ 质 with respect to the tested DR antigens, suggesting that the low RF concentrations in the patients with amyloidosis are not related to DR status. 
Arthropathies strongly associated with the occurrence of HLA-B27 are typically seronegative disorders. An increased prevalence of HLA-B27 has also been reported in Finnish patients with $\mathrm{RA}+\mathrm{A},{ }^{45}$ in patients with $\mathrm{RA},{ }^{20}$ as well as in the Finnish population in general. ${ }^{20}$ Thus the possible relation between the low $R F$ concentrations found in the patients with RA+A and HLA-B27 deserves consideration. Although there was a tendency towards accumulation of B27 among the patients with $\mathrm{RA}+\mathrm{A}$, the prevalence of B27 did not differ significantly from that in patients with RA without amyloidosis or that in the control population. Our findings are thus unlikely to be related to HLA-B27. This conclusion is also supported by the results of the RF concentrations among the control patients with RA, who were seropositive in about $80 \%$ of the cases, a finding which corresponds with those in patient series from countries with no increased prevalence of HLA-B27 among patients with RA. We do not know the reason for the discrepancies in the HLA-B27 results with respect to the patients with $\mathrm{RA}+\mathrm{A}$, but it is noteworthy that special effort was made to exclude patients with ankylosing spondylitis from the RA+A patient group.

The biological role of RFs is not known. They are low affinity antibodies with specificity for the antigenic determinants in the Fc region of $\mathrm{IgG}$. RFs are found at low concentrations in normal sera and at high concentrations in several autoimmune and infectious diseases. ${ }^{21}$ RFs are part of the immunological network ${ }^{22}$ and may facilitate the clearance of immune complexes. ${ }^{23}$ Although seropositivity at the onset of RA implies a poorer prognosis, ${ }^{24}{ }^{25}$ several studies have failed to show a relation between IgM RF titres and disease activity. ${ }^{26-30}$ Demonstration of an association between amyloid disease and RF negativity in adult RA may be interpreted to mean some protective role of RFs, at least with respect to the development of amyloid, or, more likely, that seronegativity and the development of amyloid may be related to similar genetic factors yet unknown. The findings that about $30-40 \%$ of the patients with $\mathrm{RA}+\mathrm{A}$, depending on the immunoglobulin class of the RFs, were seropositive and that a few of them also had high concentrations of IgM, IgA, or IgG RF demonstrate that the amyloid disease is not directly related to RFs. It has previously been pointed out that seronegative RA represents a disease entity clinically and immunogenetically different from seropositive RA. ${ }^{31}$ This study strengthens that view.

We are indebted to Dr Anna-Liisa Mäkelä for providing clinical data on the patients with JRA. Financial support was provided by the Sigrid Jusélius Foundation, Finland.

\section{References}

1 Glenner G G. Amyloid deposits and amyloidosis. The $\beta$ fibrilloses. $N$ Engl $J$ Med 1980; 302: 1283-92, 1333-42.

2 Maury C P J. A review of reactive (secondary) amyloidosis and its pathogenesis. Rheumatol Int 1984; 5: 1-7.

3 Woo P. O’Brien J, Robson M. Ansell B M. A genetic marker for systemic amyloidosis in juvenile arthritis. Lancet 1987; ii: 767-9.

4 Pasternack A. Tiilikainen A. HLA-B27 in rheumatoid arthritis and amyloidosis. Tissue Antigens 1977: 9: 80-9.

5 Pasternack A. Tiilikainen A. Koskimies S. HLA antigens in amyloidosis secondary to rheumatoid arthritis. In: Glenner G G, Costa P P. Freitas F, eds. Amyloid and amyloidosis. Amsterdam: Excerpta Medica, 1980: 200-4.

6 Wafin F, Wegelius O, Falck H, Koskimies S. The HLA antigens in patients with amyloidosis secondary to rheumatic diseases. In: Glenner G G, Costa P P. Freitas F, eds. Amyloid and amyloidosis. Amsterdam: Excerpta Medica, 1980: 205-6.

7 Maury C P J. Teppo A-M. Rheumatoid factors and amyloidosis in rheumatoid arthritis. $\mathrm{Br}$ Med $J$ 1985; 291: 1915-6.

8 Ropes M W. Bennett G A. Cobb S. Jacox R. Jessar R A. Revision of the diagnostic criteria for rheumatoid arthritis. 1958 revision. Ann Rheum Dis 1959: 18: 49-53.

9 Wernick R. Lospalluto J J. Fink C W, Ziff M. Serum IgG and IgM rheumatoid factors by solid phase radioimmunoassay. A comparison between adult and juvenile rheumatoid arthritis. Arthritis Rheum 1981: 24: 1501-11.

10 Amos D, Bashir H, Boyle W, McQueen M, Tiilikainen A. A simple microcytotoxicity test. Transplantation 1969:7: 220-3.

11 Tiwari J L. Terasaki P I. HLA and disease associations. New York: Springer, 1985: 18-27.

12 Häyry $P$, von Willebrand $E$, Taskinen $E$, Höckerstedt $K$, Ahonen $\mathbf{J}$, Eklund $\mathbf{B}$. Is uremia immunosuppressive in renal transplantation? Transplantation 1982; 34: 268-72.

13 Pope R M. Lessard J. Nunnery E. Differential effects of therapeutic regimens on specific classes of rheumatoid factor. Ann Rheum Dis 1986; 45: 183-9.

14 Hanly J G. Hassan J. Whelan A. Feighery C, Bresnihan B. Effects of gold therapy on the synthesis and quantity of serum and synovial fluid IgM. IgG, and IgA rheumatoid factors in rheumatoid arthritis patients. Arthritis Rheum 1986; 29: 480-7.

15 Stastny P. Association of the B-cell alloantigen DRw4 with rheumatoid arthritis. $N$ Engl J Med 1978; 298: 869-71.

16 Panayi G S, Wooley P. Batchelor J R. Genetic basis of rheumatoid disease: HLA antigens, disease manifestations and toxic reactions to drugs. $B r$ Med $J$ 1978; ii: $1326-8$.

17 Ohta N, Nishimura Y K. Tanimoto K, et al. Association between HLA and Japanese patients with rheumatoid arthritis. Hum Immunol 1982: 5: 123-32.

18 Hakala $\mathrm{M}$, van Assendelft A $\mathrm{H} \mathrm{W}$, Ilonen J, Jalava S Tiilikainen A. Association of different HLA antigens with various toxic effects of gold salts in rheumatoid arthritis. Ann Rheum Dis 1986; 45: 177-82.

19 Jaraquemada D, Ollier W, Awad J, et al. HLA and rheumatoid arthritis: a combined analysis of 440 British patients. Ann Rheum Dis 1986; 45: 627-636.

20 Isomäki H, Koota K, Martio J, Nissilä M, Tiilikainen A. HLA27 and arthritis. Ann Clin Res 1975: 7: 138-45.

21 Carson D A. Pasquali J L. Tsoukas C D, et al. Physiology and pathology of rheumatoid factors. Springer Semin Immunopathol 1981; 4: 161-79.

22 Kunkel H G, Posnett D N, Pernis B. The anti-immunoglobulins and their idiotypes: are they part of the immune network? Ann NY Acad Sci 1983: 418: 324-9.

23 Abruzzo J L, Christian C L. The induction of a rheumatoid factor-like substance in rabbits. J Exp Med 1961; 114: 791-806.

24 Jacoby R K, Jayson M I V, Cosh J A. Onset, early stages and prognosis of rheumatoid arthritis: a clinical study of 100 patients with 11-year follow-up. Br Med J 1973; ii: 96-100. 
25 Masi A T. Maldonado-Cocco J A. Kaplan S B. Fergenbaum S L. Chandler R W. Prospective study of the early course of rhcumatoid arthritis in young adults: comparison of patients with and without rhcumatoid factor positivity at entry and identification of variables correlating with outcome. Semin Arthritis Rheum 1976: 5: 299-326.

26 Lessard J. Nunnery E. Cecere F. McDuffy S, Pope R M. Relationship between the articular manifestations of rheumatoid arthritis and circulating immune complexes by three methods and specific classes of rheumatoid factors. J Rheumatol 1983: 10: 411-7.

27 Withrington R H. Teitsson I, Valdimarsson H, Seifert M H. Prospective study of early rheumatoid arthritis. II. Association of rheumatoid factor isotypes with fluctuations in disease activity. Ann Rheum Dis 1984: 43: 679-85.
28 Huskisson E C. Berry $H$. Some immunological changes in rheumatoid arthritis among patients receiving penicillamine and? gold. Postgrad Med J 1974; 50 (suppl): 59-61.

29 Rudge S R, Pound J D, Bossingham D H. Powell R J. Class specific rheumatoid factors in rheumatoid arthritis: response to chrysotherapy and relationship to disease activity. $J$ Rheumato 1985: 12: 432-6.

30 Dixon J S. Pickup M E. Lowe J R, Hallett C. Lee M R, Wright $\overparen{D}$ V. Discriminatory indices of response of patients with rheumatoid arthritis treated with D-penicillamine. Ann Rheum Dises 1980; 39: 301-11.

31 Alarcon G S, Koopman W J, Acton R T, Barger B O. Seronegative rhcumatoid arthritis. A distinct immunogenetic diseasc? Arthritis Rheum 1982; 25: 502-7. 